\title{
Unraveling the influence of arbuscular mycorrhizal colonization on arsenic tolerance in Medicago: Glomus mosseae is more effective than $G$. intraradices, associated with lower expression of root epidermal Pi transporter genes
}

\author{
Helle M. Christophersen ${ }^{\dagger}$, F. Andrew Smith and Sally E. Smith* \\ Soils Group, School of Agriculture, Food and Wine, The University of Adelaide, Adelaide, SA, Australia
}

\section{Edited by:}

Andrew Meharg, University of

Aberdeen, UK

Reviewed by:

Henk Schat, Vrije Universiteit Amsterdam, Netherlands

Brent Kaiser, The University of

Adelaide, Australia

*Correspondence:

Sally E. Smith, Soils Group, School of Agriculture, Food and Wine, The University of Adelaide, Prescott Building, Waite Campus, Adelaide, SA 5005, Australia.

e-mail: sally.smith@adelaide.edu.au

${ }^{+}$Present address:

Helle M. Christophersen, GeneWorks

Pty Ltd., 39 Winwood Street,

Thebarton, SA 5031, Australia.
We used medic (Medicago truncatula) to investigate effects of inoculation with two arbuscular mycorrhizal (AM) fungi and application of arsenate (AsV) and phosphate (Pi) on mechanisms underlying increased tolerance (in terms of growth) of AM plants to AsV. We tested the hypotheses that (1) inoculation with AM fungi results in down-regulation of MtPht1;1 and MtPht1;2 genes (encoding high-affinity Pi and AsV uptake systems in the direct root epidermal pathway) and up-regulation of the AM-induced MtPht1;4 (responsible for transfer of $\mathrm{Pi}$ from the arbuscular interface to cortical cells), and (2) these changes are involved in decreased As uptake relative to $P$ uptake and hence increased As tolerance. We also measured expression of MtMT4, a Pi starvation-inducible gene, other genes encoding Pi uptake systems (MtPht 1;5 and MtPht1;6) and arsenate reductase (MtACR) and phytochelatin synthase (MtPCS), to gain insights into broader aspects of $P$ transfers in AM plants and possible detoxification mechanisms. Medic responded slightly to AM colonization in terms of growth in the absence of As, but positively in terms of $\mathrm{P}$ uptake. Both growth and $P$ responses in AM plants were positive when As was applied, indicating As tolerance relative to non-mycorrhizal (NM) plants. All AM plants showed high expression of MtPT4 and those inoculated with Glomus mosseae showed higher selectivity against As (shown by P/As molar ratios) and much lower expression of MtPht1;1 (and to some extent MtPht1;2) than Glomus intraradices-inoculated or NM plants. Results are consistent with increased P/As selectivity in AM plants (particularly those inoculated with $G$. mosseae) as a consequence of high P uptake but little or no As uptake via the AM pathway. However, the extent to which selectivity is dependent on down-regulation of direct Pi and AsV uptake through epidermal cells is still not clear. Marked up-regulation of a PCS gene and an ACR gene in AM plants may also be involved and requires further investigation.

Keywords: arsenate, Medicago truncatula, arbuscular mycorrhizal fungi, Glomus intraradices, Glomus mosseae phosphate, Pi transporter

\section{INTRODUCTION}

Arsenic (As) is toxic to both plants and animals, so that entry into and movement through food chains pose significant problems for human health (Heikens et al., 2007; Zhao et al., 2010). In consequence, considerable attention is being paid to the mechanisms by which As is absorbed and redistributed in plants, as well as to strategies that may reduce uptake and/or provide a basis for remediation of contaminated soils (Heikens et al., 2007; Zhao et al., 2009, 2010). Here we focus on arsenate (AsV), which is the main arsenic species occurring in aerobic soils. Arsenate is an analog of orthophosphate $(\mathrm{Pi})$ and both $\mathrm{AsV}$ and $\mathrm{Pi}$ are absorbed by the same Pi transporters in the root hairs and epidermis (Heikens et al., 2007; Zhao et al., 2009, 2010). Most research, particularly that carried out in solution culture, has focused on AsV uptake via this direct pathway and on the way that Pi may compete with it. However, the majority of plants grown in non-sterile soil form arbuscular mycorrhizas (Smith and Read, 2008) which provide an additional, arbuscular mycorrhizal (AM) pathway by which nutrients, particularly $\mathrm{P}$, are absorbed and transported to root cortical cells via the AM fungus (Smith et al., 2011). The AM pathway is distinct from the direct pathway; it involves different cell types, different Pi transporters, and is likely to be separately regulated (Smith and Smith, 2011; Smith et al., 2011). Although the AM pathway is potentially capable of transporting As, new knowledge of the interplay between the activities of direct and AM pathways is beginning to reveal the mechanisms underlying the effects that $\mathrm{AM}$ symbioses have in ameliorating the toxic effects of $\mathrm{AsV}$ on plant growth (Christophersen et al., 2009a; Smith et al., 2010).

Arbuscular mycorrhizal symbioses ameliorate As toxicity and AM plants consistently show higher $\mathrm{P} / \mathrm{As}$ ratios in tissues than 
non-mycorrhizal (NM) counterparts (see Smith et al., 2010 for references). This indicates that the uptake pathways in AM and NM plants discriminate differently between Pi and AsV. Previously we used barley (Hordeum vulgare) as the host for the AM fungus Glomus intraradices because this plant does not respond positively to the symbioses in terms of growth or P uptake; hence interpretation of effects of the symbiosis on $\mathrm{Pi}$ and $\mathrm{AsV}$ uptake were not confounded by markedly different sizes and $\mathrm{P}$ nutrition of the AM and NM plants (Christophersen et al., 2009a). It is known that the AM pathway plays a major role in uptake of $\mathrm{Pi}$ by barley (Zhu et al., 2003; Grace et al., 2009), and that activity of the direct pathway is concurrently reduced because there is no increase in total P uptake per plant (see Smith et al., 2009; Smith et al., 2011). In the work of Christophersen et al. (2009a), the reduction of direct pathway activity in AM plants was associated with lower expression of the epidermal Pi transporters ( $H v P h t 1 ; 1$ and $H v P h t 1 ; 2)$ involved in $\mathrm{Pi}$ and AsV uptake, while the expression of the AM-inducible transporter $\mathrm{HvPht1;8}$, responsible for Pi uptake by root cortical cells in the AM pathway, was highly up-regulated and unaffected by As application. AM plants had lower specific AsV uptake (uptake per unit weight of root) and higher P/As ratios in shoots than NM plants. Results supported the hypothesis that down-regulation of the direct pathway lowers both AsV and Pi uptake via that route, while activity of the AM pathway in Pi uptake compensates for lower Pi uptake via the direct pathway but transports little or no As.

Most work on the effects of AM symbiosis on As toxicity has been done with plant species that grow larger and take up more $\mathrm{P}$ when AM, compared with NM counterparts. In such species, the AM pathway delivers large amounts of $\mathrm{P}$ to the plant and effects of AM colonization in decreasing $\mathrm{P}$ (and potentially As) delivery via the direct pathway are not as clear as they are in non-responsive plants such as barley. If there is no functional down-regulation of the direct pathway in responsive AM plants, then specific uptake of AsV by this route should remain unchanged, but overall discrimination of uptake in favor of $\mathrm{Pi}$ (and hence increased P/As ratios) would be provided by high delivery of $\mathrm{P}$ and low (or negligible) delivery of As via the AM pathway, as suggested by Christophersen et al. (2009a). Previous work has consistently shown higher specific $\mathrm{P}$ uptake in AM-responsive plants in the presence of As, compared with NM counterparts. However, effects on specific As uptake ranged from decreases (Ultra et al., 2007) to increases (Liu et al., 2005; Xia et al., 2007), with several reports of no effects (Ahmed et al., 2006; Pope, 2006; Pope et al., 2007; Xia et al., 2007). These differences leave open the question of whether down-regulation of the direct pathway is involved in lowering AsV uptake. In this paper we examined this hypothesis by investigating the effects of AM colonization by two different AM fungi on As toxicity in and $\mathrm{Pi}$ and $\mathrm{AsV}$ uptake by medic (Medicago truncatula), a plant that frequently responds positively to AM colonization in terms of growth and $\mathrm{P}$ uptake. We used soil $\mathrm{P}$ levels designed to lower these responses. We made concurrent measurements of the expression of plant Pi transporters in the direct pathway $(M t P h t 1 ; 1$ and $M t P h t 1 ; 2)$ and the AM-inducible $\mathrm{Pi}$ transporter gene MtPht1;4 (involved in operation of the AM pathway). We also examined the expression of two other genes encoding $\mathrm{P}$ transporters in roots (MtPht1;5 and $M t P t h 1 ; 6)$, whose expression patterns and responses to $\mathrm{P}$ supply and AM colonization are less well known (see Grunwald et al., 2009). Expression of a P starvation response gene MtMT4 (Burleigh and Harrison, 1998) and of two genes potentially involved in As detoxification mechanisms [a phytochelatin synthase (PCS) gene and an arsenate reductase (ACR gene)] were also included to check whether the treatments influenced $\mathrm{P}$ starvation at the molecular level and whether the As detoxification mechanisms were influenced by AM colonization (see Table 1).

Glomus intraradices was chosen as one AM fungal symbiont because it was the fungus used in our previous experiments with barley (Christophersen et al., 2009a,b) and M. truncatula (Pope et al., 2007) and Glomus mosseae because it has been used with several different responsive plant species in many of the previous investigations of effects of AM fungi on As toxicity (e.g., Liu et al., 2005; Ahmed et al., 2006; Chen et al., 2007; Xia et al., 2007).

\section{MATERIALS AND METHODS}

SOIL

A low P, fine sandy loam from an undisturbed and unfertilized site within the cemetery at Mallala, South Australia, was collected from the top $20 \mathrm{~cm}$ and passed through a $5-\mathrm{mm}$ sieve. Soil and fine quartz sand were separately sterilized by autoclaving twice over 3 days at $121^{\circ} \mathrm{C}$ for $1 \mathrm{~h}$. The Mallala loam contained $13.8 \mathrm{mg} \mathrm{P} \mathrm{kg}^{-1}$ (Olsen P) (Olsen et al., 1954). In addition it contained $1.7 \mathrm{~g} \mathrm{~kg}^{-1}$ total $\mathrm{N}, 731 \mathrm{mg} \mathrm{K} \mathrm{kg}^{-1}$, and $10.3 \mathrm{mg} \mathrm{S} \mathrm{kg}^{-1}$; the $\mathrm{pH}$ was $7.7\left(\mathrm{CaCl}_{2}\right)$. Soil was mixed with sand in the ratio of 1:9 (soil: fine sand). This mix will be referred to as soil hereafter. Additional $\mathrm{P}$ was applied as $\mathrm{KH}_{2} \mathrm{PO}_{4}$ to provide additional 10 and $20 \mathrm{mg} \mathrm{P} \mathrm{kg}^{-1}$ soil, referred to as Low P (LP) and High P (HP) hereafter. $\mathrm{P}$ was added to reduce both the likelihood of serious $\mathrm{P}$ deficiency and the probability of very large size differences between $\mathrm{AM}$ and $\mathrm{NM}$ plants. For addition of $\mathrm{AsV}, \mathrm{KH}_{2} \mathrm{AsO}_{4}$ was added to provide 2.5 and $5 \mathrm{mg} \mathrm{As} \mathrm{kg}^{-1}$ soil. These $\mathrm{P}$ and As levels were chosen based on our previous work showing that they permit colonization by AM fungi (Christophersen, H. M., unpublished). The soil was incubated for 1 week to allow the ions to equilibrate with the soil.

\section{INOCULUM}

Glomus intraradices Schenck and Smith DAOM181602 (WFVAM10) and G. mosseae (Nicol. \& Gerd.) Gerdemann \& Trappe BEG161 (WFVAM45) were used as the AM fungal symbionts. Inoculum was produced in pot cultures with clover (Trifolium subterraneum L.) in the same soil as used for the main experiment. No Rhizobium was added. Pots received $10 \mathrm{ml} \mathrm{week}^{-1}$ of half-strength Long Ashton solution minus $\mathrm{P}$ (Cavagnaro et al., 2001) and containing twice the concentration of $\mathrm{NaNO}_{3}$ in order to suppress nodulation. Plants were grown for $8-12$ weeks and then allowed to dry down until used. Clover grown under similar conditions with no added AM fungal inoculum was used as NM mock inoculum. Before drying roots were cored and colonization recorded. The inoculum, a dry crude pot culture material containing soil, roots, spores, and hyphae, was thoroughly mixed with the soil at a rate of $10 \% \mathrm{w} / \mathrm{w}$. The NM pots were prepared as described for AM pots by adding dry mock inoculum. 
Table 1 | Summary of information ${ }^{1}$ on genes chosen for expression analysis in medic (Medicago truncatula) plants.

\begin{tabular}{|c|c|c|c|c|c|}
\hline $\begin{array}{l}\text { Gene name } \\
\text { (abbreviation) }\end{array}$ & Identity & Tissue location & Affinity for Pi & Effect of increased $P$ & Effect of AM status of roots ${ }^{2}$ \\
\hline MtMT4 & $\begin{array}{l}\text { Non-coding RNA, involved } \\
\text { in Pi-deprivation signaling } \\
\text { pathway }\end{array}$ & Roots & NA & Decreased & Decreased \\
\hline MtPht1;1 (PT1) & Pi transporter & $\begin{array}{l}\text { Root epidermis and } \\
\text { cortex }\end{array}$ & Low & Slowly decreased & Decreased \\
\hline MtPht1;4 (PT4) & Pi transporter & AM root cortex & Low & Not known & Large increase \\
\hline MtPht1;5 (PT5) & Pi transporter & $\begin{array}{l}\text { Root epidermis } \\
\text { cortex and vascular } \\
\text { tissue }\end{array}$ & High & Rapidly decreased & Maintained or decreased \\
\hline$M t P C S^{3}$ & Phytochelatin synthase & No previous information & & & \\
\hline
\end{tabular}

'Information on phosphate transporters and MtMT4 based on Burleigh and Harrison (1999), Burleigh and Harrison (1998), Grunwald et al. (2009), Javot et al. (2007), Liu et al. (2008). For arsenate reductase and phytochelatin synthase see text.

${ }^{2}$ Differential effects depending on fungal identity have been reported in some cases.

${ }^{3}$ Putative genes for which no previous information is available. For sequence identification procedure, see text.

\section{EXPERIMENTAL DESIGN}

The experiment had a factorial design, with As and $\mathrm{P}$ levels and inoculation as factors. Three As levels $\left(0,2.5\right.$, and $5 \mathrm{mg} \mathrm{As} \mathrm{kg} \mathrm{mg}^{-1}$ soil), two P levels ( 10 and $20 \mathrm{mg} \mathrm{P} \mathrm{kg}^{-1}$ soil), and three inoculation treatments (NM, G. intraradices and G. mosseae) were included. The $\mathrm{P}$ and As treatments are henceforth abbreviated as LP and $\mathrm{HP}$ and $0 \mathrm{As}, 2.5 \mathrm{As}$, and 5 As. Each treatment was replicated five times. Pots were arranged randomly on a glasshouse bench and randomly rearranged twice weekly during the growth period to take into account variations in environmental conditions.

\section{SEED STERILIZATION, PLANT GROWTH, AND SAMPLE COLLECTION}

Seeds of M. truncatula L. cv. Jemmalong were surface-sterilized in household bleach for $10 \mathrm{~min}$, rinsed with reverse osmosis (RO) water and placed on wet sterilized filter paper for 2 days at $25^{\circ} \mathrm{C}$, in the dark. One germinated seed was planted per pot. One seedling had to be replaced 2 days after planting, using a seedling grown in a mock-inoculated pot at LP. Plants were grown for 6 weeks in a semi-controlled glasshouse under natural light from July to August (Southern Hemisphere winter). The glasshouse temperature was set at $22 \pm 2{ }^{\circ} \mathrm{C}$ (day) and at $14 \pm 2{ }^{\circ} \mathrm{C}$ (night). The soil was maintained at field capacity [ $5 \%$ water $(\mathrm{w} / \mathrm{w})$ for this soil] by watering to weight with half-strength Long Ashton solution minus P (modified as above). The concentration of $\mathrm{ZnSO}_{4}$ was increased 2.3 times because a previous experiment showed that the $\mathrm{Zn}$ concentration in shoots of 5-week-old medic supplied with half-strength Long Ashton nutrient solution was slightly lower than adequate (Christophersen, H. M., unpublished) and it is known that Zn deficiency has effects on $\mathrm{P}$ transporter expression and other aspects of $\mathrm{P}$ nutrition (Huang et al., 2000). Additional $\mathrm{N}$ was supplied as $\mathrm{NH}_{4} \mathrm{NO}_{3}$ at the rate of $5,10,15$, and $15 \mathrm{mg} \mathrm{N}$ per pot after 2, 3, 4, and 5 weeks, respectively, to account for the increasing $\mathrm{N}$ demand (Smith et al., 2004).

Plants were destructively harvested at 6 weeks. One day before harvest subsamples of roots were collected by coring the pots on each side of the plant with a 1-cm diameter corer. The cored roots from each pot were quickly washed in RO water, mixed thoroughly, and then divided into two samples for extraction of RNA and determination of percent root length colonized by AM fungi. Fresh weights (FW) of these samples were recorded in order to calculate the total root dry weight (RDW) after the destructive harvest. Roots for RNA extraction were fast frozen in liquid nitrogen and stored at $-80^{\circ} \mathrm{C}$. Roots for determination of colonization were stored in 50\% ethanol until further processing (see below). At harvest, shoots were cut from the plants, rinsed, and blotted. Roots were washed in tap water and rinsed in $0.1 \mathrm{M} \mathrm{HCl}$ solution, followed by a thorough rinse in $\mathrm{RO}$ water to ensure that As was removed from the surface of the roots (Marin et al., 1992) and patted dry with paper towels. FW of both shoots and residual roots were recorded before drying at $85^{\circ} \mathrm{C}$ for $48 \mathrm{~h}$ to obtain shoot dry weight (SDW) and residual RDW. Tissue $\mathrm{P}$ and As concentrations were determined by Radial CSIROS inductively coupled plasma atomic emission spectroscopy (ICP-AES, see below). Total RDW was determined from the root FW/DW ratio of the residual samples and the total FW of all root samples. Two plants in the HP, 5 As, and NM treatment group grew very poorly and were omitted from the analysis. Therefore this treatment group only had three replicates.

\section{ASSESSMENT OF AM COLONIZATION}

Roots in 50\% ethanol were rinsed thoroughly with RO water and cleared in $10 \% \mathrm{KOH}$ for 3 days at room temperature and then for 
3 min at $90^{\circ} \mathrm{C}$. They were stained with 5\% Schaeffer black ink in 5\% white vinegar for $3 \mathrm{~min}$ at $90^{\circ} \mathrm{C}$ and de-stained in acidified water (Vierheilig et al., 1998). Between each step the roots were put on ice and then rinsed in $\mathrm{RO}$ water. Roots were maintained in acidified water until they were mounted on slides in glycerol. Percent colonization, including development of arbuscules, was determined according to the magnified intersects method (McGonigle et al., 1990) and mock-inoculated roots were thoroughly checked for lack of colonization under a dissecting microscope.

\section{TISSUE DIGESTION AND ANALYSIS}

Weighed samples of oven-dried plant tissue were digested with nitric/perchloric acid and analyzed by ICP-AES, by the Waite Analytical Services (University of Adelaide, SA, Australia). Some samples were analyzed in duplicate to give an indication of the homogeneity of the samples. The percent variation between the duplicate samples was less than $0.5 \%$ for both $\mathrm{P}$ and As.

Total uptake (micromoles per plant) and specific uptake (micromoles absorbed per gram RDW) of $\mathrm{P}$ and As and $\mathrm{P} / \mathrm{As}$ ratios were calculated on a molar basis to highlight possible interactions between orthophosphate $(\mathrm{Pi})$ and arsenate $(\mathrm{AsV})$.

\section{RNA EXTRACTIONS}

RNA was extracted using a QIAGEN RNeasy Plant Mini Kit (QIAGEN Pty Ltd., Doncaster, VIC, Australia) following the manufacturer's instructions. The RNA extractions included the QIAGEN “on the column” RNAse-Free DNAse treatment. In addition extracted RNA was DNAse treated using the TURBO DNA-free ${ }^{\mathrm{TM}}$ kit (Applied Biosystems/Ambion, Austin, TX, USA) following the manufacturer's instructions to remove any remains of genomic DNA. RNA integrity was tested by running RNA on a $1.2 \%$ agarose gel and validation of the ribosomal RNA bands. RNA was quantified using a QuantiT ${ }^{\mathrm{TM}}$ RNA assay kit and Invitrogen Qubit Fluorimeter.

\section{REVERSE TRANSCRIPTION}

For optimal use of 18S-ribosomal RNA (18S-RNA) as housekeeping gene (HKG), cDNA was synthesized using an mRNA and 18S-RNA co-application reverse transcription (Co-RT) method described by Zhu and Altmann (2005). The Affinity Script quantitative real-time PCR (QPCR) cDNA synthesis kit (Stratagene, La Jolla, CA, USA) was used for the RT reactions. Different concentrations $(0.2,1$, or $5 \mu \mathrm{M})$ of the 18S-RNA universal primer, NS21 (Simon et al., 1992), and the oligo-(dT) primer $(0.3 \mu \mathrm{g})$ were tested with 0.25 and $0.5 \mu \mathrm{g}$ of total RNA as described by Zhu and Altmann (2005). The optimized combination of primers for the Co-RT reaction was $0.2 \mu \mathrm{M}$ of NS21 and $0.3 \mu \mathrm{g}$ of oligo-(dT) primer. Each $20 \mu \mathrm{l}$ RT reaction included $0.5 \mu \mathrm{g}$ of total RNA. The RT program was: $5 \mathrm{~min}$ at $25^{\circ} \mathrm{C}, 5 \mathrm{~min}$ at $42^{\circ} \mathrm{C}, 15 \mathrm{~min}$ at $55^{\circ} \mathrm{C}$, and $5 \mathrm{~min}$ at $95^{\circ} \mathrm{C}$. cDNA was stored at $-20^{\circ} \mathrm{C}$. No reverse transcriptase (NRT) controls were included, in order to assess genomic DNA contamination in the down-stream QPCR analysis.

\section{QUANTITATIVE REAL-TIME PCR}

Quantitative real-time PCR was performed using the Brilliant II QPCR master mix (Stratagene) containing SYBR green. Amplification and detection of PCR products were performed in a
MX3000P instrument (Stratagene). Twenty microliters QPCR reactions using $150 \mathrm{nmol}$ of each primer and $2 \mu \mathrm{l}$ templates were set up according to manufacturer's instructions. Primers (for details, see Table 2) were designed using the NCBI Primer3 primer design tool ${ }^{1}$ or Beacon designer (obtained as a service from Integrated Sciences). HPLC-purified primers were synthesized by Operon Biotechnologies $\mathrm{GmbH}^{2}$. In addition to $\mathrm{Mt} 18 \mathrm{~S}$ we chose to include $M t E L F 1$ and $M t c y c l$ because, from our experience with barley, they show stable expression in roots upon inoculation with G. intraradices and in the presence of As (Christophersen et al., 2009b). In addition these two genes showed stable expression in medic inoculated with either G. intraradices or Gigaspora margarita at 0 and $10 \mathrm{mg} \mathrm{P} \mathrm{kg}^{-1}$ soil (Christophersen, H. M., unpublished data). The cDNAs were diluted 1:10 for detection of the genes of interest (GOI), 1:100 for detection of HKG MtELF1 and Mtcycl and 1:10000 for detection of the HKG, Mt18S. The Lotus japonicus EST contig number TC65916 was identified by keyword-searching "phytochelatin" in the L. japonicus DFCI Gene Index ${ }^{3}$. Blasting of TC65916 to the M. truncatula DFCI Gene Index identified the medic putative phytochelatin synthetase (MtPCS) with the contig number TC116338 (TC115338 no longer current, now replaced by TC175804). The EST (contig number TC118619) encoding the putative arsenate reductase, MtACR, was found by a blast search using an Arabidopsis ACR (CDC25) gene to the $M$. truncatula DFCI Gene Index.

The QPCR cycling program was initiated with $10 \mathrm{~min}$ at $95^{\circ} \mathrm{C}$ to activate the polymerase, followed by 40 cycles of $95^{\circ} \mathrm{C}$ for $30 \mathrm{~s}$, $60^{\circ} \mathrm{C}$ for $30 \mathrm{~s}$, and $72^{\circ} \mathrm{C}$ for $30 \mathrm{~s}$ for the GOI. For Mt18S the annealing temperature was $61^{\circ} \mathrm{C}$ for $20 \mathrm{~s}$. Analysis of all samples was performed with three technical replications. The normalized relative quantity (NRQ) was determined using the software qBasePlus version 2.1 (Biogazelle, Belgium). Analysis of the reference genes tested in qBasePlus using geNorm revealed that the $M t 18 S$ was too variable across samples and accordingly only $\mathrm{MtCycl}$ and MTELF1 were used as HKG.

\section{STATISTICAL ANALYSES}

Since some data distributions did not fulfill the assumptions of normality and/or homogeneity of variances for a parametric ANOVA we used PERMANOVA (Anderson, 2005), a distancebased permutation procedure. We used Euclidean distances as recommended for univariate analyses (M. Anderson, personal communication) followed by the corresponding a posteriori pair-wise comparison tests (McArdle and Anderson, 2001).

\section{RESULTS}

\section{AM COLONIZATION AND PLANT GROWTH}

Mock-inoculated plants remained non-mycorrhizal (NM; results not shown). Plants inoculated with G. intraradices or G. mosseae formed arbuscular mycorrhizas, with percent root length colonized in the range $43-73 \%$ (Table 3 ). There was no effect of $\mathrm{P}$ on colonization. However, the interaction between As and inoculation was significant $(P=0.001)$ and indicated decreased colonization

\footnotetext{
${ }^{1}$ http://www.ncbi.nlm.nih.gov/tools/primer blast/index.cgi?LINK_LOC = BlastHome ${ }^{2}$ https://www.operon-biotech.com/index.php

${ }^{3}$ http://compbio.dfci.harvard.edu/tgi/plant.html
} 
Table 2 | Details of primers used in Quantitative real-time PCR analysis of gene expression in medic (Medicago truncatula).

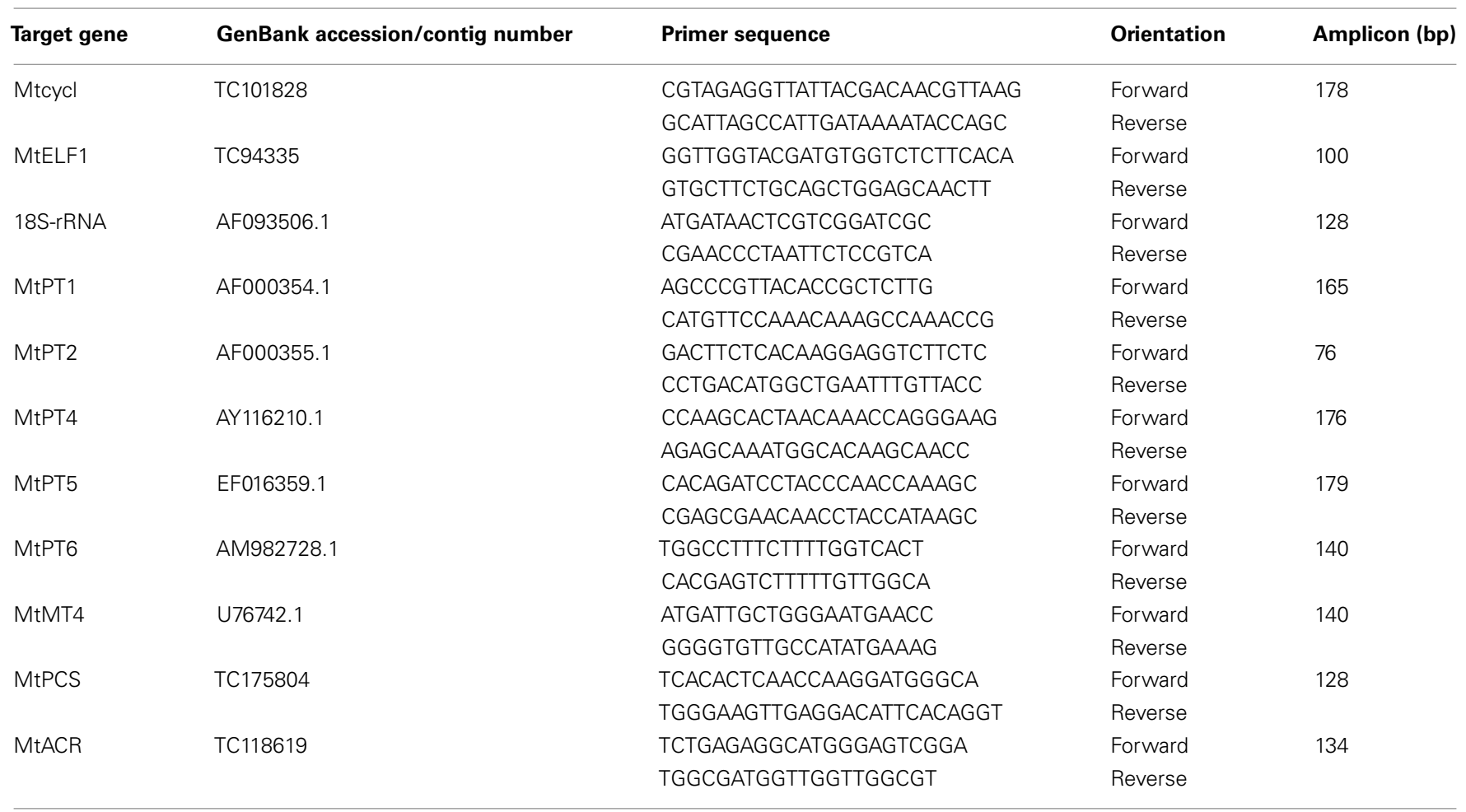

Table 3 | Percent root length colonized in medic (Medicago truncatula) grown in pots with two levels of phosphorus $\left(P ; 10\right.$ and $20 \mathrm{mg} \mathrm{P} \mathrm{kg}^{-1}$ soil) with no addition of arsenate (0) or AsV added at the rates of 2.5 and 5 mg As $\mathrm{kg}^{-1}$ soil.

\begin{tabular}{lll}
\hline As level (mg As kg & $\mathbf{- 1}$ soil) & \multicolumn{2}{c}{ Percent root length colonized } \\
\cline { 2 - 3 } & G. intraradices & G. mosseae \\
\hline 0 & $73.4 \pm 1.7^{\mathrm{a}}$ & $65.1 \pm 2.8^{\mathrm{ab}}$ \\
2.5 & $56.6 \pm 4.9^{\mathrm{b}}$ & $62.1 \pm 3.5^{\mathrm{ab}}$ \\
5.0 & $42.7 \pm 4.0^{\mathrm{c}}$ & $60.7 \pm 3.8^{\mathrm{ab}}$ \\
\hline
\end{tabular}

The effect of $P$ on percent colonization was not significant, while the interaction between inoculation and arsenate addition $(A s)$ was $(P=0.001)$. Inoculated plants from the two $P$ treatments were analyzed together; mock-inoculated plants were not colonized and have been omitted. Data are presented as mean \pm SEM $(n=10)$. Values with the same letters indicate no significant difference between treatments.

of plants inoculated with $G$. intraradices with increasing As levels, while the colonization of plants inoculated with $G$. mosseae was unaffected (Table 3). There were no differences in percent root length containing arbuscules between the fungi at 0 As or in response to $\mathrm{P}$ application. However, there was a slight reduction in percent root length containing arbuscules of $G$. intraradices at 2.5 As and of both fungi at 5 As (results not shown).

Shoot and root DW are shown in Figure 1. The interaction between inoculation, $\mathrm{P}$, and As with respect to SDW was significant $(P=0.040)$. In the absence of As ( 0 As) NM plants responded positively to the application of $\mathrm{P}$, but there were no significant responses to $\mathrm{P}$ in AM plants. At LP there was a small positive mycorrhizal growth response (MGR) to inoculation with G. mosseae, but not to G. intraradices. At HP AM plants grew significantly less well than NM plants (negative MGR).

Application of As generally reduced SDW, most markedly in NM plants and at 5 As. SDW of NM plants and plants inoculated with G. intraradices were markedly lower at 5 As than at 2.5 As. Plants inoculated with $G$. mosseae also showed lower growth at 5 As than at 2.5 As but the reduction was only significant at HP. Because the growth of NM plants was negatively impacted by As application there were larger differences in DW between NM and AM plants as As application increased at both LP and HP (i.e., MGRs increased). This effect was consistent at both P levels and both As levels for plants inoculated with G. mosseae, but only at 2.5 As for plants inoculated with $G$. intraradices.

For RDW the interaction between $\mathrm{P}$ and inoculation was significant $(P=0.007)$, as was the overall effect of As $(P=0.0001)$. At LP the RDW of plants inoculated with $G$. intraradices was lower than for NM plants, but that of plants inoculated with G. mosseae was unaffected. At HP RDW of NM plants increased, but that of AM plants did not and there was no difference between the two AM treatments (Figure 1, insert).

\section{UPTAKE OF P AND As}

$P$ concentrations were generally higher in AM plants than NM plants within each P and As treatment, with values for G. mosseae in many cases higher than those for $G$. intraradices. Values for shoots in NM plants were higher than those in roots (Table 4). Hence, $\mathrm{P}$ content (Figure 2A) showed similar trends to plant dry weight, but differences were more marked. The interaction 

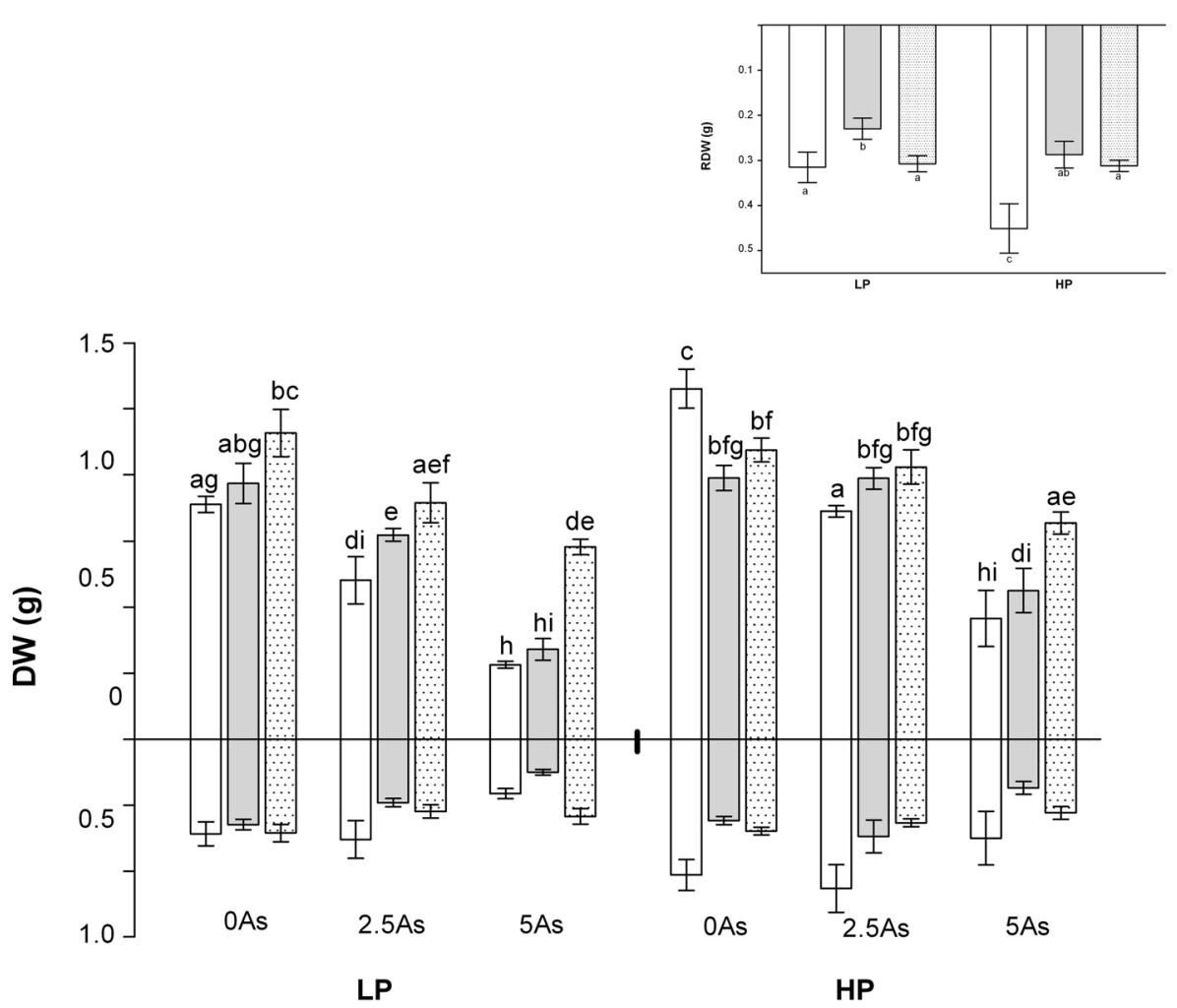

FIGURE 1 | Shoot (above $x$-axis) and root (below $x$-axis) DW of non-mycorrhizal (open bars) and arbuscular mycorrhizal (G. intraradices, gray bars and G. mosseae, dotted bars) medic (Medicago truncatula) grown in pots with different phosphorus $(P)$ levels, 10 and $20 \mathrm{mg} \mathrm{P}^{\mathbf{1}} \mathbf{~ g}^{-1}$ soil (LP and HP, respectively) and with no arsenic (As) added to the soil (0 As), or at rates of 2.5 and $5 \mathrm{mg} \mathrm{As} \mathrm{kg}^{-1}$ soil (2.5 As and 5 As respectively).
Data are presented as mean values \pm SEM ( $n=5$ except for treatment group NM, HP5As where $n=3$ ). The interaction between all factors (P, As, and inoculation) was significant $(P=0.040)$ for SDW. The interaction between $P$ and inoculation on RDW (illustrated in insert) was significant $(P=0.007)$ and independent of the effect of As $(P=0.0001)$. In each figure the same letters indicate no significant difference between treatment groups at the $5 \%$ level. between inoculation, $\mathrm{P}$ and As on $\mathrm{P}$ content was significant $(P=0.005)$. Inoculation with $G$. mosseae markedly increased $\mathrm{P}$ content in the plants at all As additions and at both $\mathrm{P}$ levels compared with equivalent NM plants. Plants inoculated with $G$. intraradices had intermediate $\mathrm{P}$ contents that were significantly higher than NM plants and lower than G. mosseae-inoculated plants at LP and at HP5As. At HP2.5As $\mathrm{P}$ contents of $G$. intraradices- and G. mosseae-inoculated plants were similar and higher than those of NM plants.

For specific $\mathrm{P}$ uptake (Figure 3A) the interaction between inoculation and As was significant $(P=0.001)$. Hence there was significantly increased specific $\mathrm{P}$ uptake in AM plants compared with NM plants at 0 As and higher specific uptake in plants inoculated with G. mosseae than G. intraradices. Specific P uptake was also higher in AM plants compared to NM plants when As was added to the soil, but there was no difference between the different As treatments. Application of As lowered specific P uptake in NM plants but not in AM plants.

No As was detected in plants that grew at 0 As and these were excluded from PERMANOVA analyses. All plants took up As when As was applied to the soil (Table 4). Arsenic concentrations were very much higher in roots than in shoots, as observed many times previously (Table 4). At LP2.5As only a single replicate of each mycorrhizal treatment contained detectable As in the shoots. The interaction between inoculation and As application on As content was significant $(P=0.006)$. Increasing As application from 2.5 As to 5 As increased As content of NM plants slightly and of AM plants to a greater extent (Figure 2B). At 2.5 As AM inoculation had no effect on As content, but at 5 As both groups of AM plants had higher As contents than NM.

For specific As uptake the interaction between inoculation and As application was significant $(P=0.0001)$. In all inoculation treatments specific uptake of As was higher at 5 As than at 2.5 As, regardless of $\mathrm{P}$ application (Figure 3B). At 2.5 As values for all AM plants were slightly but significantly higher than $\mathrm{NM}$, whereas at 5 As there were clear differences between plants inoculated with G. intraradices and G. mosseae. Thus, whereas $G$. intraradices consistently increased specific As uptake compared with NM plants, the only significant increase in specific uptake of As in G. mosseae-inoculated plants was at 2.5 As.

In general $\mathrm{P}$ concentrations were lower and As concentrations higher in NM compared with AM plants in both roots and shoots in each $\mathrm{P}$ and As treatment (Table 4). Hence, $\mathrm{P} / \mathrm{As}$ molar ratios at 2.5 As were higher in AM than NM plants, with effects of $G$. mosseae more marked than those of $G$. intraradices (Figure 4). At 5 As all $\mathrm{P} /$ As ratios within inoculation treatments were lower 
Table 4 | $\mathrm{P}$ and As concentrations ( $\mu \mathrm{mol} \mathrm{g} \mathrm{DW}^{-1}$ ) in shoots and roots of medic (Medicago truncatula) grown at two different $\mathrm{P}$ supplies (10 and $20 \mathrm{mg} \mathrm{P} \mathrm{kg}^{-1}$ soil) and three As supplies (0, 2.5, and $5.0 \mathrm{mgAs} \mathrm{kg}^{-1}$ soil).

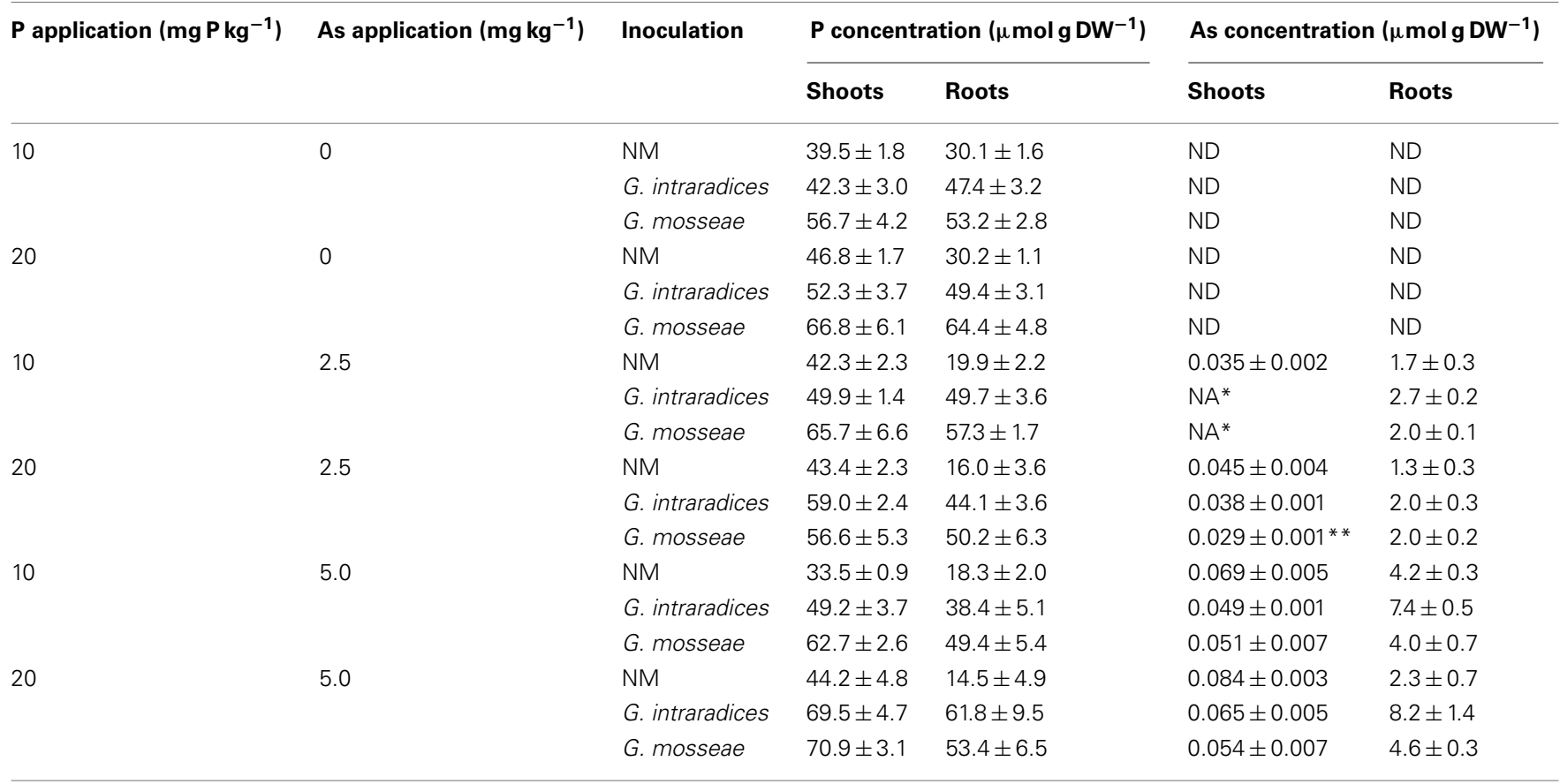

ND, not detectable, below detection limit; NA, not applicable; *Four out of five replicates were below detection limit; **Two out of five replicates below detection limit, therefore replaced by mean of the three positive values.

Data are presented as means \pm SEM ( $n=5$ except for treatment group NM, HP5As where $n=3$ ).

(Figure 4). G. mosseae-inoculated plants again had P/As ratios that were higher than NM or G. intraradices-inoculated plants. Ratios in shoots were very much lower than roots, as expected from the low amounts of As transferred to shoots (results not shown).

\section{GENE EXPRESSION}

MtMT4 (MT4) is a non-coding gene whose expression is negatively related to the $\mathrm{P}$ status of the plant (see Table 1). Consistent with this, MT4 expression was significantly lower at HP than LP, with lower expression also in AM than NM plants at both $\mathrm{P}$ levels (Figure 5). These findings show that changes in plant $\mathrm{P}$ status following $\mathrm{P}$ application and inoculation were detected at the molecular level. However, within each inoculation treatment As application had no significant effects on MtMT4 expression (results not shown).

Expression of MtPht1;1 (PT1) is shown in Figure 6. The interaction between inoculation, $P$, and As was significant $(P=0.045)$. Expression was generally lower in plants inoculated with $G$. mosseae compared to NM plants, but significantly lower than in plants inoculated with $G$. intraradices only at LP0As and HP5As. Plants inoculated with $G$. intraradices had lower expression than NM plants only at LP5As, HP0As, and HP5As.

The interaction between the factors $\mathrm{P}$ and As on expression of MtPht1;2 (PT2) was significant $(P=0.001)$, as was the overall effect of inoculation $(P=0.0001)$. Results indicated highest expression of PT2 in plants grown at LP and 5 As. There was no significant effect of $\mathrm{P}$ application on PT2, regardless of inoculation. The overall effect of inoculation on PT2 was lower expression in plants inoculated with G. mosseae compared to NM plants and plants inoculated with $G$. intraradices (results not shown).

Expression of $M t P h t 1 ; 4$ (PT4) is shown in Figure 7. The interaction between inoculation, $P$, and As was significant $(P=0.002)$. Plants inoculated with either $G$. intraradices or $G$. mosseae had markedly and significantly higher expression of PT4 than NM plants; most of the latter showed very low or undetectable expression. The expression of PT4 in plants inoculated with G. mosseae was similar over the different treatments and generally lower than in plants inoculated with G. intraradices. Plants inoculated with $G$. intraradices showed similar consistent PT4 expression at $\mathrm{HP}$, but at LP expression decreased with increasing application of AsV.

In general expression of MtPht1;5 (PT5) did not vary greatly across treatments (results not shown). However, the effects of inoculation and As were significant $(P=0.001)$, as was the overall effect of $\mathrm{P}(P=0.0001)$. The lowest expression was in plants grown with HP. The interaction between inoculation and As indicated lower expression of PT5 in NM plants when As was added to the soil. Plants inoculated with $G$. intraradices showed similar expression levels regardless of As addition, while plants inoculated with G. mosseae had lowest expression of PT5 at 0 As and highest expression at 5 As.

Expression of MtPht1;6 (PT6) was significantly affected by inoculation $(P=0.0001)$ showing lower expression in plants inoculated with either $G$. intraradices or G. mosseae compared with NM plants. Neither P or As addition had any effect on PT6 expression (results not shown). 

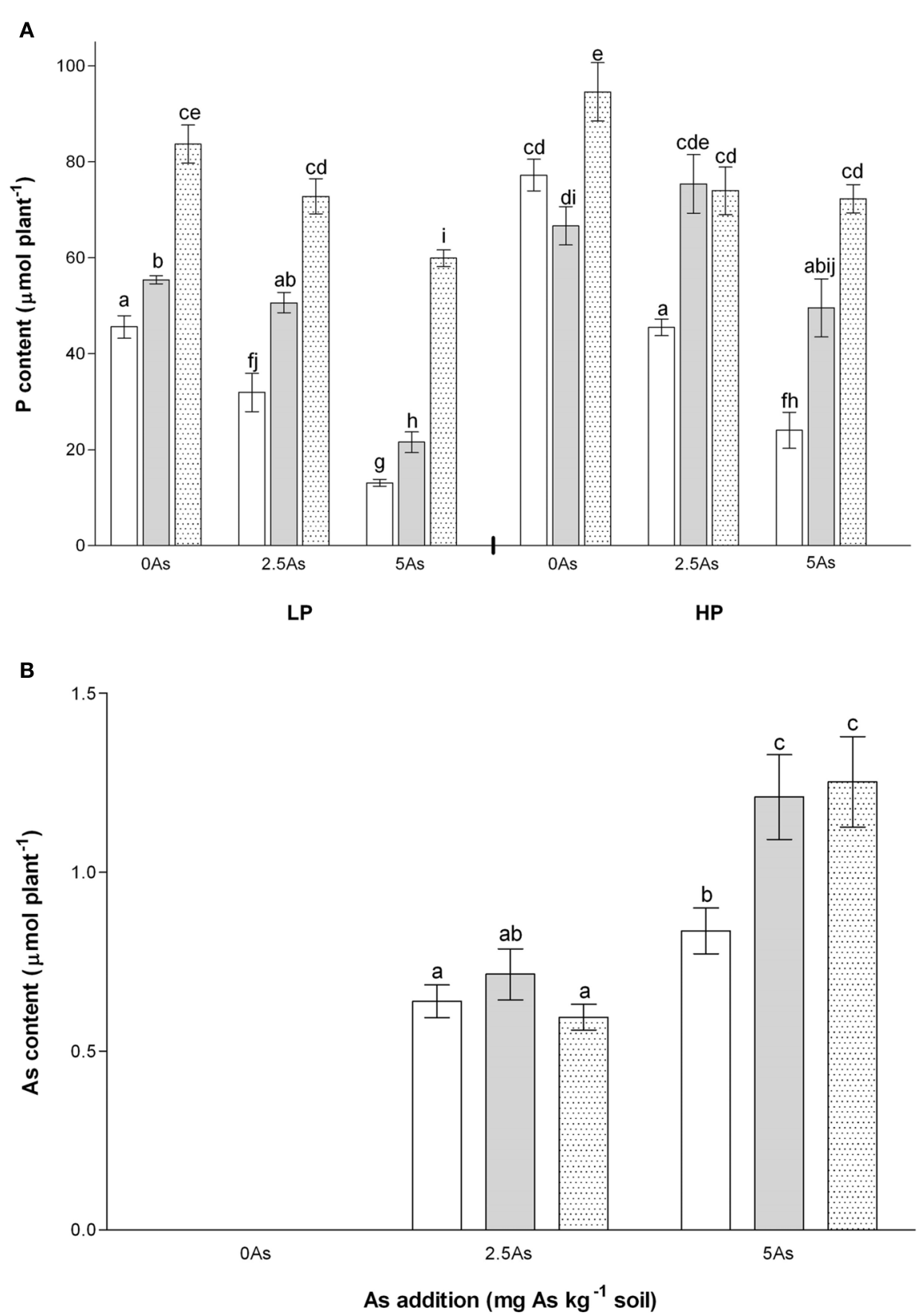

FIGURE 2 | Total $P$ content (A) and As content (B) of non-mycorrhizal (open bars) and arbuscular mycorrhizal (G. intraradices, gray bars and G. mosseae, dotted bars) medic (Medicago truncatula) grown in pots with different phosphorus (P) levels, 10 and $20 \mathrm{mg} \mathrm{P} \mathrm{kg}^{-1}$ soil (LP and $\mathrm{HP}$, respectively) and with no arsenic (As) added to the soil (0 As), or at rates of 2.5 and $5 \mathrm{mgAs} \mathrm{kg}^{-1}$ soil (2.5 As and $5 \mathrm{As}$, respectively).

Data are presented as mean values \pm SEM $[n=5$ in (A), except in treatment group NM, HP5As where $n=3 ; n=10$ in (B) except in treatment group NM, 5 As where $n=8]$. In (A), the interaction between all factors ( $P, A s$, and inoculation) was significant $(P=0.005)$. In $(B)$ no As was detectable in plants grown in the absence of As. The interaction between inoculation and As application was significant $(P=0.006)$. In each graph the same letters indicate no significant difference between treatment groups at the $5 \%$ level.
Inoculation resulted in consistent and significantly $(P=0.0001)$ higher expression of MtPCS and MtACR in AM compared with NM plants, with no significant differences between plants inoculated with $G$. intraradices or G. mosseae (Figures 8A,C). Application of $\mathrm{P}$ had no effect on expression of these genes. Application of 5 As increased expression of $M t A C R$ by about $16 \%(P=0.003$; Figure 8B).

\section{DISCUSSION}

Arbuscular mycorrhizal colonization by both fungi was relatively high and small decreases with As application only occurred in plants inoculated with $G$. intraradices, as shown previously for this plant/fungus combination (Pope et al., 2007). In most previous investigations, including those using G. mosseae, effects of As on percent root length colonized have not been widely observed 

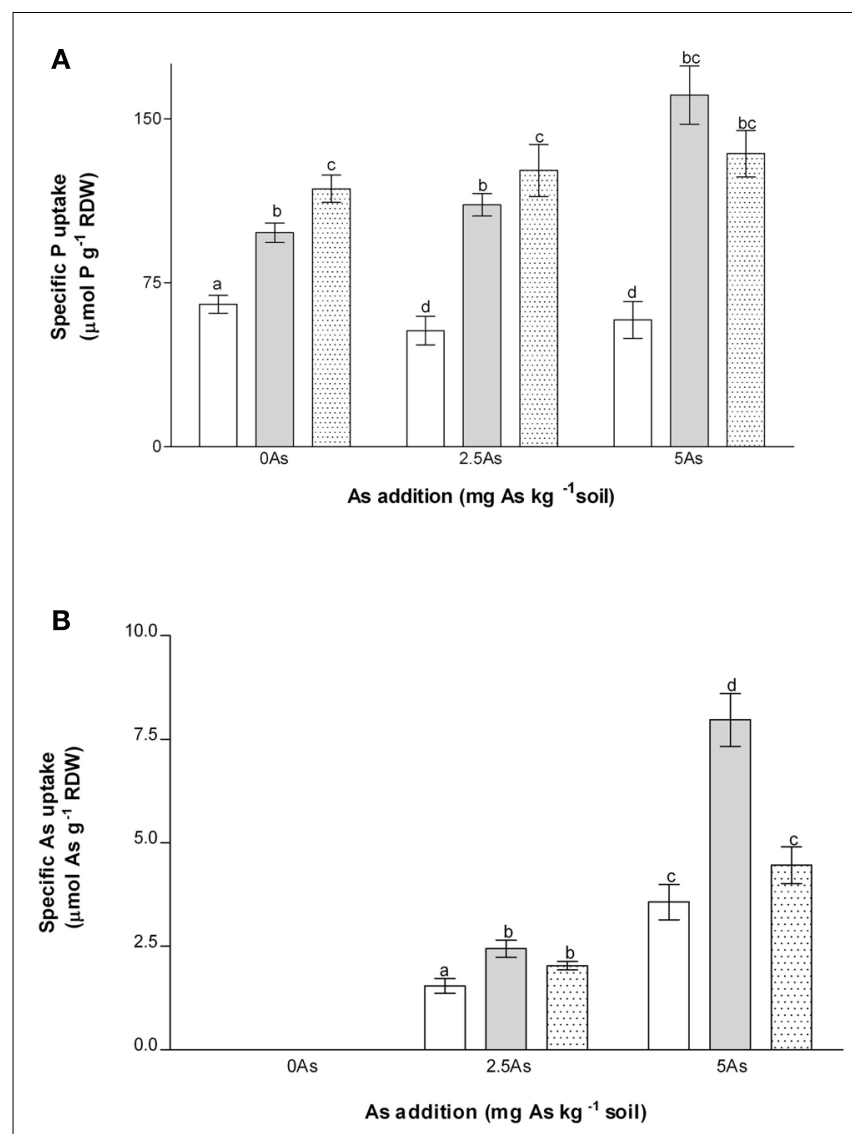

FIGURE 3 | Effects of As and inoculation on specific $P$ uptake (A) and specific As uptake (B) of non-mycorrhizal (open bars) and mycorrhizal (G. intraradices, gray bars and G. mosseae, dotted bars) medic (Medicago truncatula) grown in pots with different phosphorus (P) levels, 10 and $20 \mathrm{mg} \mathrm{P} \mathrm{kg}^{-1}$ soil (LP and HP, respectively) and with no arsenic (As) added to the soil ( $0 \mathrm{As}$ ) or at rates of 2.5 and $5 \mathrm{mg} \mathrm{As} \mathrm{kg}^{-1}$ soil (2.5 As and 5 As, respectively). Data are presented as mean values \pm SEM ( $n=10$, except for treatment group NM, 5 As where $n=8$ ). For specific $\mathrm{P}$ uptake $(\mathbf{A})$ the interactions between $\mathrm{As}$ and inoculation and between $P$ and $A$ s were significant $(P=0.001$ and 0.002 , respectively). For specific As uptake (B) the interaction between As and inoculation was significant $(P=0.0001)$. In each panel the same letters indicate no significant difference between treatment groups at the $5 \%$ level.

(Smith et al., 2010). Here the more marked effect of 5 As on total and arbuscular percent colonization by $G$. intraradices could have been related to higher concentrations of As in roots colonized by this fungus compared with those colonized by G. mosseae. Reduced expression of the AM-inducible transporter PT4 with increasing arsenic in $G$. intraradices-inoculated plants grown at low P could have been related to the reduction in colonization and arbuscule development. Both these points require further investigation.

Medic did not show large positive responses to AM colonization in terms of growth at LP0As, but there were significant positive responses to inoculation in terms of total plant $\mathrm{P}$ uptake and specific $\mathrm{P}$ uptake, with effects generally greater in plants inoculated with $G$. mosseae than with $G$. intraradices. Both these effects are reflected in higher $\mathrm{P}$ concentrations in the AM plants. Large positive responses were not expected because of the chosen $\mathrm{P}$
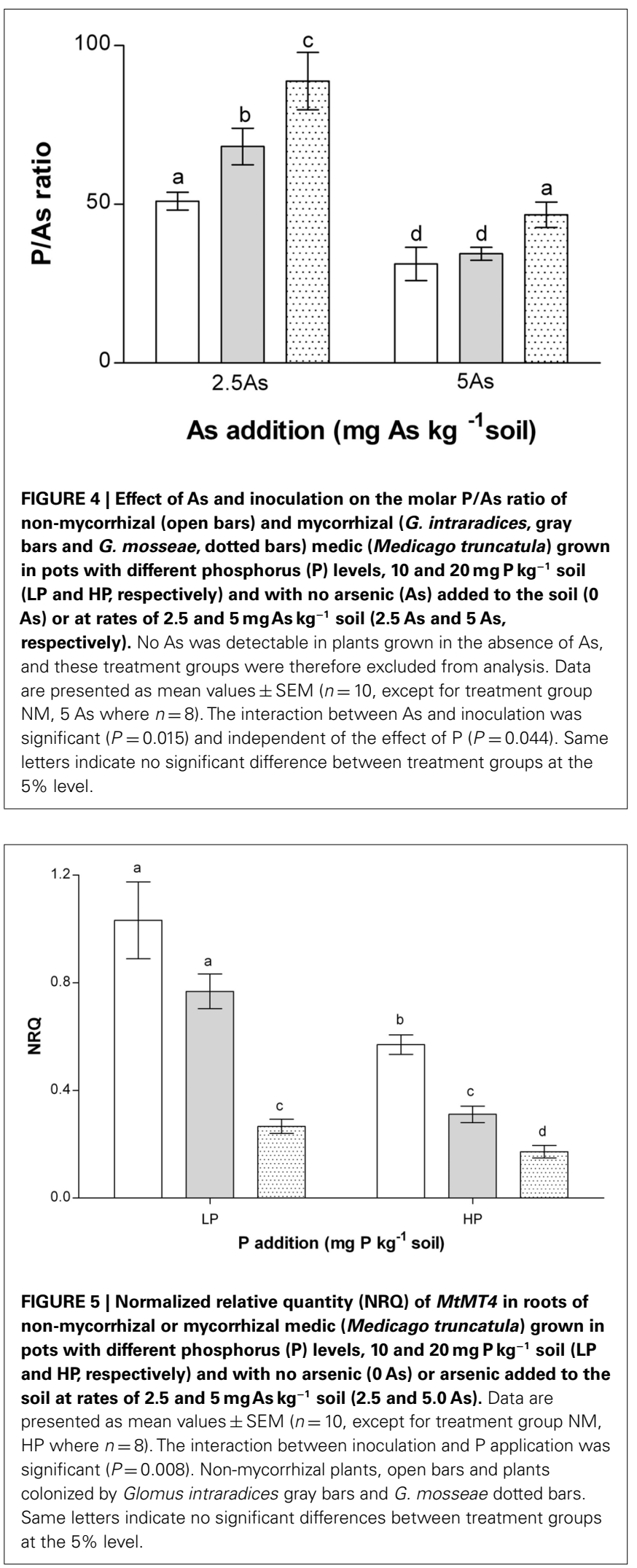

applications. With HP0As, both fungi produced small growth depressions, possibly due to carbon drain to the fungus that was 


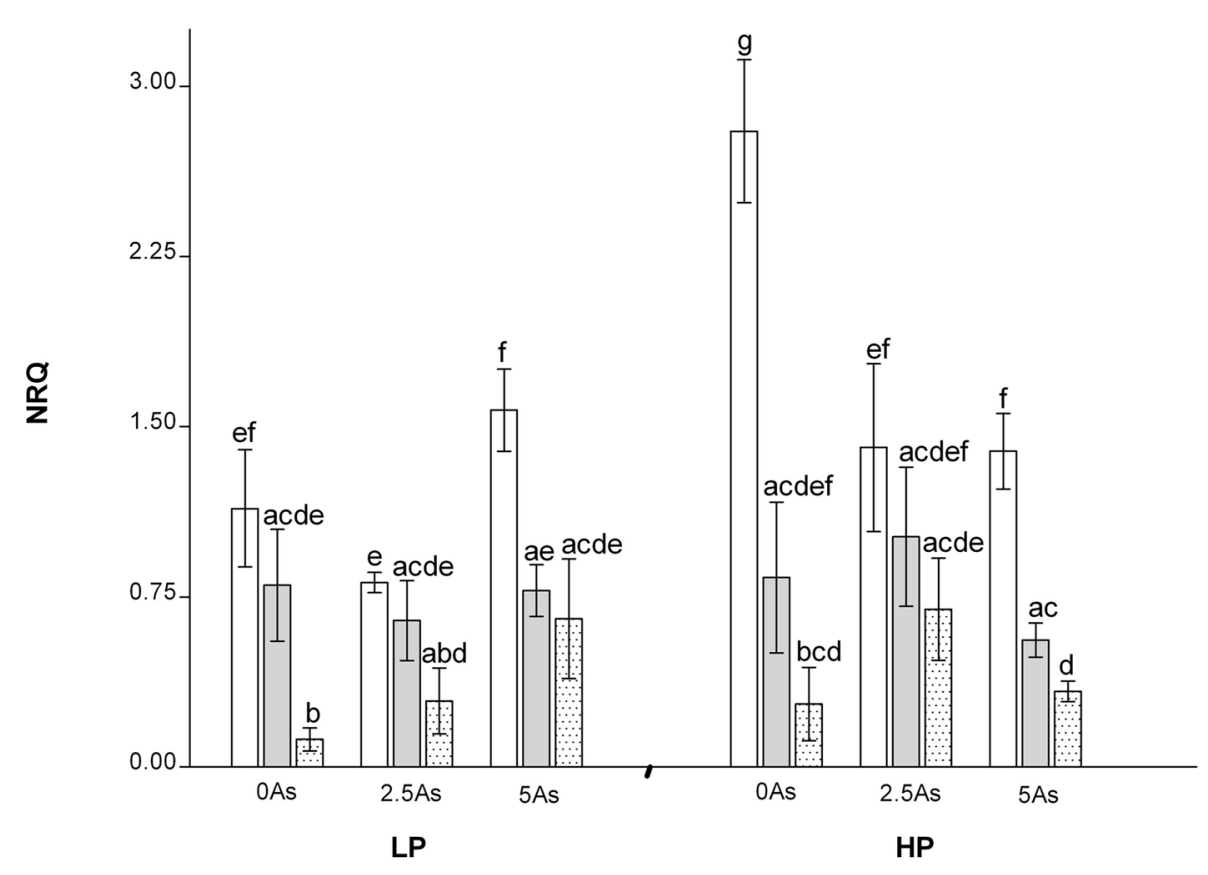

FIGURE 6 | Normalized relative quantity (NRQ) of MtPht1;1 in roots of non-mycorrhizal (open bars) and mycorrhizal (G. intraradices, gray bars and G. mosseae, dotted bars) medic (Medicago truncatula) grown in pots with different phosphorus (P) levels, 10 and $20 \mathrm{mg} \mathrm{P} \mathrm{kg}^{-1}$ soil (LP and HP, respectively) and with no arsenic (As) added to the soil ( $0 \mathrm{As}$ ) or at rates of $\mathbf{2 . 5}$ and $\mathbf{5} \mathrm{mgAs} \mathrm{kg}^{-1}$ soil (2.5 As and $\mathbf{5 ~ A s , ~ r e s p e c t i v e l y ) . ~ D a t a ~}$ are presented as mean values \pm SEM ( $n=5$, except for treatment group NM, HP5As where $n=3$ ). The interaction between all factors (P, As, and inoculation) was significant $(P=0.045)$. Same letters indicate no significant difference between treatment groups at the $5 \%$ level.

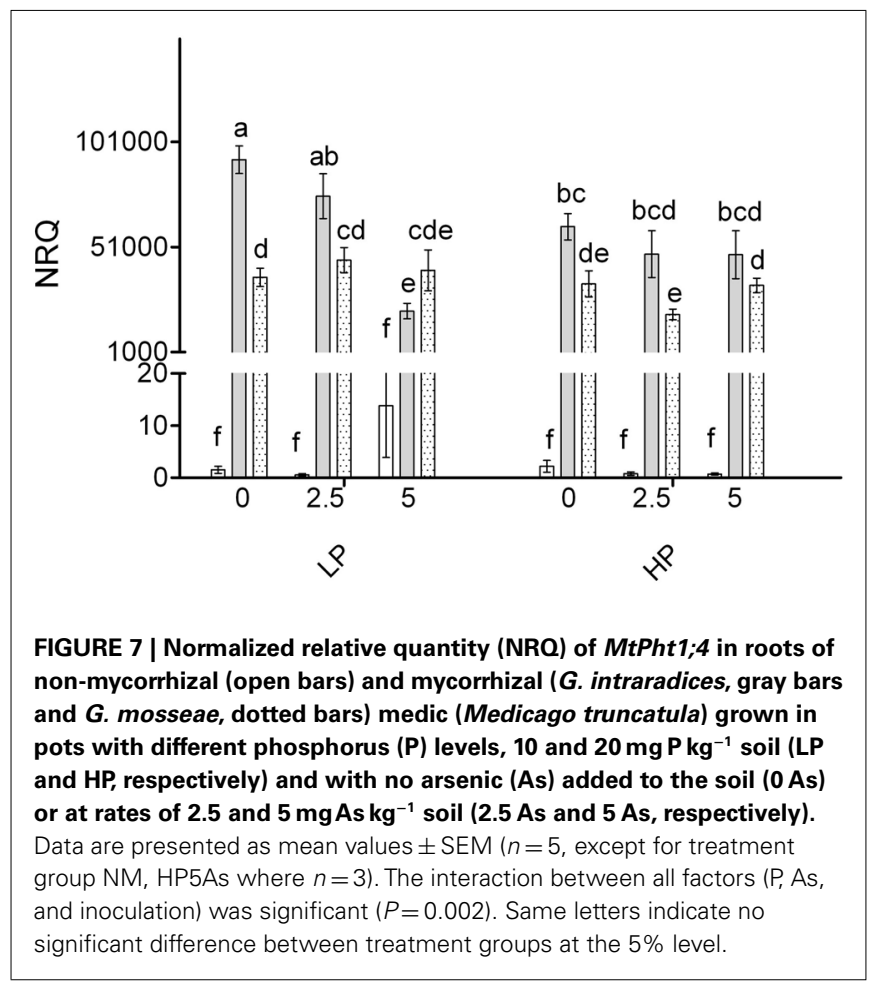

not fully compensated by $\mathrm{P}$ uptake by the AM pathway (Smith et al., 2009). Increases in $\mathrm{P}$ concentrations, $\mathrm{P}$ content, and specific
P uptake in AM plants compared with NM counterparts, together with high expression of the AM-inducible Pi transporter MtPht1;4, suggest significant delivery of $\mathrm{P}$ via the AM pathway.

The NM plants showed significant growth reductions and As toxicity as As application was increased (as shown previously, Chen et al., 2007; Pope et al., 2007). Toxicity in NM plants was significantly alleviated by additional $\mathrm{P}$ supply only at 2.5 As (see also Pope et al., 2007), but inoculation increased growth over NM controls at both levels of $\mathrm{P}$ with $\mathrm{G}$. intraradices at $2.5 \mathrm{As}$ and with G. mosseae at both 2.5 As and 5 As. These effects were associated with higher $\mathrm{P}$ concentrations, contents, and specific $\mathrm{P}$ uptake. The molar ratios of $\mathrm{P} /$ As were highest for $G$. mosseae-inoculated plants and lowest for NM plants, with $G$. intraradices-inoculated plants intermediate or equal to NM plants. Hence G. mosseae-inoculated plants showed the highest selectivity of $\mathrm{P}$ uptake over As uptake in both roots and shoots. The effect of AM colonization on increasing $\mathrm{P} /$ As selectivity is completely consistent with much previous work (Zhao et al., 2009; Smith et al., 2010) and provides the starting point for our exploration of possible mechanisms.

Our hypothesis was that the high $\mathrm{P} /$ As selectivity would be associated with continuing supply of $\mathrm{P}$, but little or no As, via the AM pathway and reduced uptake of both $\mathrm{P}$ and As via the epidermal direct pathway. The increased specific $\mathrm{P}$ uptake in AM plants and the high expression of PT4 in the AM pathway, regardless of small effects of As application on G. intraradices colonization, is consistent with this hypothesis. Furthermore, reduced expression of PT1 and PT2 in medic colonized by AM fungi (as shown here and previously in the absence of As; Liu et al., 1998; Burleigh, 


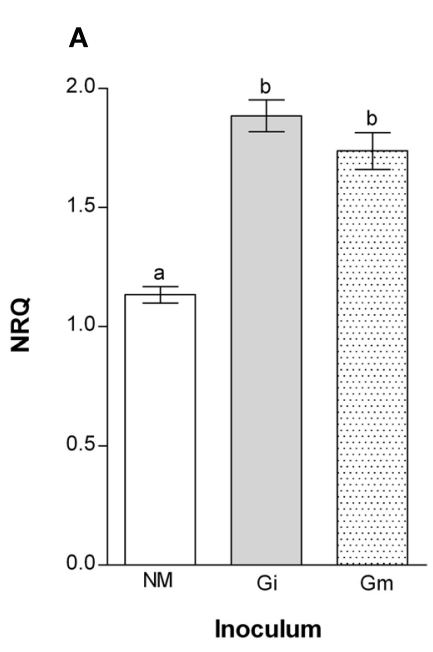

B

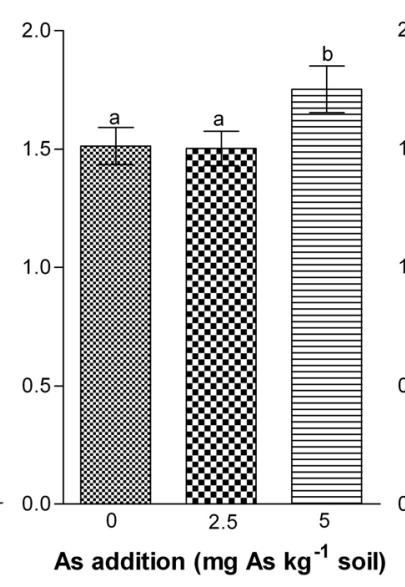

C

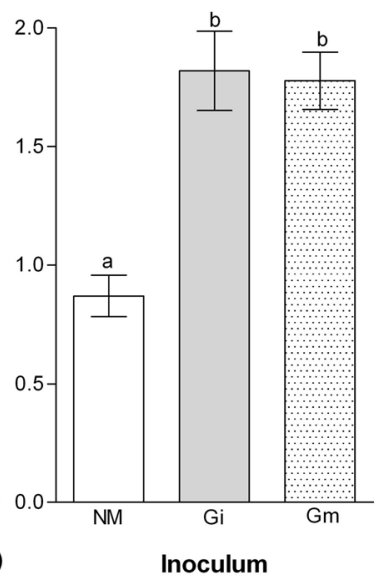

FIGURE 8 | Normalized relative quantity (NRQ) of MtACR (A,B) and MtPCS (C) in roots of medic (Medicago truncatula) grown in pots with different phosphorus $(P)$ levels, 10 and $20 \mathrm{mg} \mathrm{P} \mathrm{kg}^{-1}$ soil and with no arsenic (As) added to the soil (0 As) or at rates of 2.5 and $5 \mathrm{mg} \mathrm{As} \mathrm{kg}^{-1}$ soil (2.5 As and $\mathbf{5} \mathbf{A s}$, respectively). (A,C) Show effects of inoculation (non-mycorrhizal, NM, open bars; G. intraradices, Gi, gray bars; and $G$. mosseae, Gm, stippled bars) on expression of both MtACR and MtPCS $(P=0.0001)$. (B) shows effect of As application on MtACR $(P=0.003)$. There were no effects of $P$ application on expression of either gene. Data are presented as mean values \pm SEM ( $n=5$, except for treatment group NM, HP5As where $n=3$ ). Same letters indicate no significant difference between treatment groups at the $5 \%$ level.
2001; Chiou et al., 2001), particularly in plants inoculated with G. mosseae, suggests that activity of the direct pathway was lower than in G. intraradices-inoculated plants. This observation provides some explanation for the differential effects of the two fungi. The lower expression of both PT1 and PT2 observed here with $G$. mosseae does not agree with the findings of Grunwald et al. (2009) who showed that a different isolate of this AM fungal species had only very small effects on expression of these genes. The discrepancy may be the result of use of different HKG in the two investigations. Nevertheless, much more work is needed to sort out variations in gene expression such as this in the context of functional diversity among different plant-AM fungal combinations. Analysis of expression of the other genes encoding Pi transporters (Table 1) does not shed much further light on this issue. In G. mosseae-inoculated plants PT5 showed lower expression than other treatments at $0 \mathrm{As}$, with a significant increase as As application increased. Expression of PT6 was reduced to the same extent in AM plants with both fungi, compared with NM plants (as shown previously by Grunwald et al., 2009), but the role of this gene in $\mathrm{Pi}$ (or AsV) uptake or redistribution in plants remains obscure.

Specific As uptake by NM plants was not significantly lower at HP than LP, which would have been expected if competition between $\mathrm{Pi}$ and $\mathrm{AsV}$ was an important factor influencing As uptake. This finding suggests that competition in uptake from soil between $\mathrm{AsV}$ and $\mathrm{Pi}$ may only make a small contribution to the overall effects of P on As toxicity (see Pope et al., 2007; Christophersen et al., 2009b). Data for specific As uptake did not show the decrease in AM compared with NM plants at either P level that would be expected if lower uptake via the direct pathway and/or increased AsIII efflux are major contributors to lower AsV content and high $\mathrm{P} /$ As selectivity. Although specific As uptake was generally lower in G. mosseae-inoculated than in G. intraradicesinoculated plants neither had lower specific uptake than equivalent
NM plants. Increases in specific As uptake in G. intraradicesinoculated plants may have been the result of uptake and delivery of As via the AM pathway. However, this is inconsistent with findings for non-responsive barley using the same isolate of $G$. intraradices (Christophersen et al., 2009a) and responsive Medicago sativa, using G. mosseae (Chen et al., 2007). In both cases plants were grown in compartmented pots and results showed little or no evidence for As transfer via the AM pathway. Furthermore, if this was the explanation, higher transfer of As via $G$. mosseae would have been expected because these plants apparently had higher AM pathway activity than those inoculated with G. intraradices. The issues relating to differential activity of direct pathway and AM pathway in the context of uptake of Pi and AsV can only be readily resolved by the use of radioactive tracers of both As and Pi in compartmented pots (Smith et al., 2010).

There remains the possibility that effects of AM inoculation other than those associated with $\mathrm{Pi}$ or $\mathrm{AsV}$ uptake may be involved in As tolerance in AM plants. Here, we have provided preliminary evidence that AM colonization increases expression of two plant genes [phytochelatin synthase $(M t P C S)$ and arsenate reductase $(M t A C R)]$ that encode proteins thought to be involved in arsenate detoxification. Both Medicago genes were expressed in NM plants and showed no major induction in the presence of As. The lack of difference in expression between $G$. intraradices- and $G$. mosseae-inoculated plants does not help explain the differential effects of the two fungal symbionts in alleviating As toxicity. In the case of MtPCS the lack of effect of As is in line with previous work showing constitutive production of PCs (see Clemens and Persoh, 2009). It has been suggested that PCs are involved in metal homeostasis and that apparent roles in detoxification of As follow from this (see Clemens and Persoh, 2009; Zhao et al., 2009). Increased MtPCS expression in AM roots, as shown here, could 
be primarily related to the role of AM fungi in delivering metals such as $\mathrm{Zn}$ to the roots (Bürkert and Robson, 1994). In the case of $M t A C R$, increased expression might result in increased reduction of AsV to AsIII causing detoxification and possibly increased As transfer to the shoots (see Bleeker et al., 2006; Duan et al., 2007; Zhao et al., 2009 for references). However, increased shoot As was not detected in our analyses. The possibility that AsIII might be effluxed from either roots or AM fungal hyphae (Smith et al., 2010)

\section{REFERENCES}

Ahmed, F. R. S., Killham, K., and Alexander, I. (2006). Influences of arbuscular mycorrhizal fungus Glomus mosseae on growth and nutrition of lentil irrigated with arsenic contaminated water. Plant Soil 258, 33-41.

Anderson, M. J. (2005). PERMANOVA: A FORTRAN Computer Program for Permutational Multivariate Analysis of Variance. Auckland: Department of Statistics, University of Auckland.

Bleeker, P. M., Hakvoort, H. J. W., Bliek, M., Souer, E., and Schat, H. (2006). Enhanced arsenate reduction by a CDC25-like typrosine phosphatase explains increased phytochelatin accumulation in arsenate tolerant Holcus lanatus. Plant J. 45, 917-929.

Bürkert, B., and Robson, A. (1994). ${ }^{65} \mathrm{Zn}$ uptake in subterranean clover (Trifolium subterraneum L.) by three vesicular-arbuscular mycorrhizal fungi in a root-free sandy soil. Soil Biol. Biochem. 26, 1117-1124.

Burleigh, S. H. (2001). Relative quantitative RT-PCR to study the expression of plant nutrient transporters in arbuscular mycorrhizas. Plant Sci. 160, 899-904.

Burleigh, S. H., and Harrison, M. J. (1999). The down-regulation of Mt4-like genes by phosphate fertilization occurs systemically and involves phosphate translocation to the shoots. Plant Physiol. 119, 241-248.

Burleigh, S. M., and Harrison, M. J. (1998). Characterization of the Mt4 gene from Medicago truncatula. Gene 216, 47-53.

Cavagnaro, T. R., Smith, F. A., Lorimer, M. F., Haskard, K. A., Ayling, S. M., and Smith, S. E. (2001). Quantitative development of Paristype arbuscular mycorrhizas formed between Asphodelus fistulosus and Glomus coronatum. New Phytol. 149, 105-113.

Chen, B. D., Xiao, X., Zhu, Y. G., Smith, F. A., Xie, Z. M., and Smith, S. E. (2007). The arbuscular mycorrhizal fungus Glomus mosseae gives contradictory effects on phosphorus and arsenic acquisition by Medicago sativa Linn. Sci. Total Environ. 379, 226-234.

Chiou, T.-J., Liu, H., and Harrison, M. J. (2001). The spatial expression patterns of a phosphate transporter (MtPT1) from Medicago truncatula indicate a role in phosphate transport at the root/soil interface. Plant J. 25, 281-293.

Christophersen, H. M., Smith, F. A., and Smith, S. E. (2009a). Arbuscular mycorrhizal colonization reduces arsenate uptake in barley via downregulation of transporters in the direct epidermal phosphate uptake pathway. New Phytol. 184, 962-974.

Christophersen, H. M., Smith, S. E., Pope, S., and Smith, F. A. (2009b). No evidence for competition between arsenate and phosphate for uptake from soil by medic or barley. Environ. Int. 35, 485-490.

Clemens, S., and Persoh, D. (2009). Multi-tasking phytochelatin synthases. Plant Sci. 177, 266-271.

Duan, G.-L., Zhou, Y., Tong, Y.-P., Mukhopadhyay, R., Rosen, B. P., and Zhu, Y.-G. (2007). A CDC25 homologue from rice functions as an arsenate reductase. New Phytol. 174, 311-321.

Grace, E. J., Cotsaftis, O., Smith, F. A., Tester, M., and Smith, S. E. (2009). Arbuscular mycorrhizal inhibition of growth in barley cannot be attributed to extent of colonisation, fungal $\mathrm{P}$ uptake or effects on plant phosphate transporter expression. New Phytol. 181, 938-949.

Grunwald, U., Guo, W., Fischer, K., Isayenkov, S., Ludwig-Müller, J., Hause, B., Yan, X.-L., Küster, H., and Franken, P. (2009). Overlapping expression patterns and differential transcript levels of phosphate transporter genes in arbuscular mycorrhizal, Pi-fertilised and phytohormone-treated Medicago truncatula roots. Planta 229, 1023-1034.

Heikens, A. M., Panaullah, G. M., and Meharg, A. A. (2007). "Arsenic behaviour from groundwater and soil to crops: Impacts on agriculture and food safety," in Reviews of Environmental Contamination and

is not likely because AM colonization did not decrease specific As uptake. Roles of both genes in alleviating As toxicity and more generally in metal binding in AM plants require further research.

\section{ACKNOWLEDGMENTS}

We thank the Australian Research Council for funding (Grant \# 06ARC_DP0662916), Dr. Evelina Facelli for statistical advice, and Rebecca Stonor for technical assistance.

Toxicology, Vol. 189, ed. G. W. Ware (New York: Springer), 43-87.

Huang, C., Barker, S. J., Langridge, P., Smith, F. W., and Graham, R. D. (2000). Zinc deficiency up-regulates expression of high-affinity phosphate transporter genes in both phosphate-sufficient and -deficient barley roots. Plant Physiol. 124, 415-422.

Javot, H., Pumplin, N., and Harrison, M. J. (2007). Phosphate in the arbuscular mycorrhizal symbiosis: transport properties and regulatory roles. Plant Cell Environ. 30, 310-322.

Liu, H., Trieu, A. T., Blaylock, L. A., and Harrison, M. J. (1998). Cloning and characterization of two phosphate transporters from Medicago truncatula roots: regulation in response to phosphate and response to colonization by arbuscular mycorrhizal (AM) fungi. Mol. Plant Microbe Interact. 11, 14-22.

Liu, J., Versaw, W. K., Pumplin, N., Gomez, S. K., Blaylock, L. A., and Harrison, M. J. (2008). Closely related members of the Medicago truncatula PHT1 phosphate transporter gene family encode phosphate transporters with distinct biochemical activities. J. Biol. Chem. 283, 24673-24681.

Liu, Y., Zhu, Y.-G., Chen, B.-D., Christie, P., and Li, X.-L. (2005) Yield and arsenate uptake of arbuscular mycorrhizal tomato colonized by Glomus mosseae BEG167 in As-spiked soil under glasshouse conditions. Environ. Int. 31, 867-873.

Marin, A. R., Masscheleyn, P. H., and Patrick, W. H. (1992). The influence of chemical form and concentration of arsenic on rice growth and tissue arsenic concentration. Plant Soil 139, 175-183.

McArdle, B. H., and Anderson, M. J. (2001). Fitting multivariate models to community data: a comment on distance-based redundancy analysis. Ecology 82, 290-297.

McGonigle, T. P., Miller, M. H., Evans, D. G., Fairchild, G. L., and Swan, J. A. (1990). A new method which gives an objective measure of colonization of roots by vesicular-arbuscular mycorrhizal fungi. New Phytol. 115, 495-501.

Olsen, S. R., Cole, C. V., Watanabe, F. S., and Dean, L. A. (1954). Estimation of Available Phosphorus in Soils by Extraction with Sodium Bicarbonate. USDA Circular No. 939, Washington.

Pope, S. (2006). Increased Phosphate Supply and Mycorrhizal Colonisation Increase Growth and P Status of Medicago Truncatula in ArsenicContaminated Soil but do not Reduce As Uptake. Honours thesis, Soil and Land Systems, School of Earth and Environmental Sciences, The University of Adelaide, Adelaide.

Pope, S., Smith, S. E., Christophersen, H. M., and Smith, F. A. (2007). "Arsenic uptake by Medicago truncatula: $\mathrm{P}$ supply and arbuscular mycorrhizal (AM) colonization do not reduce specific uptake from soil," in Biogeochemistry of Trace Elements: Environmental Protection, Remediation and Human Health, eds Y.G. Zhu, N. Lepp, and R. Naidu (Beijing: Tsinghua University Press), 863-864.

Simon, L., Lalonde, M., and Bruns, T. D. (1992). Specific amplification of $18 \mathrm{~S}$ fungal ribosomal genes from vesicular-arbuscular endomycorrhizal fungi colonizing roots. Appl. Environ. Microbiol. 58, 291-295.

Smith, F. A., Grace, E. J., and Smith, S. E. (2009). More than a carbon economy: nutrient trade and ecological sustainability in facultative arbuscular mycorrhizal symbioses. New Phytol. 182, 347-358.

Smith, S. E., Christophersen, H. M., Pope, S., and Smith, F. A. (2010). Arsenic uptake and toxicity in plants: integrating mycorrhizal influences. Plant Soil 327, 1-21.

Smith, S. E., Jakobsen, I., Grønlund, M., and Smith, F. A. (2011) Roles of arbuscular mycorrhizas in plant phosphorus nutrition: interactions between pathways of phosphorus uptake in arbuscular mycorrhizal roots have important implications for understanding and manipulating plant phosphorus acquisition. Plant Physiol. 156, 1050-1057. 
Smith, S. E., and Read, D. J. (2008). Mycorrhizal Symbiosis, 3rd Edn. New York: Academic Press.

Smith, S. E., and Smith, F. A. (2011). Roles of arbuscular mycorrhizas in plant nutrition and growth: new paradigms from cellular to ecosystem scales. Annu. Rev. Plant Biol. 62, 227-250.

Smith, S. E., Smith, F. A., and Jakobsen, I. (2004). Functional diversity in arbuscular mycorrhizal (AM) symbioses: the contribution of the mycorrhizal P uptake pathway is not correlated with mycorrhizal responses in growth or total P uptake. New Phytol. 162, 511-524.

Ultra, V. U., Tanaka, S., Sakurai, K., and Iwasaki, K. (2007). Effects of arbuscular mycorrhiza and phosphorus application on arsenic toxicity in sunflower (Helianthus annuus L.) and on the transformation of arsenic in the rhizosphere. Plant Soil 290, 29-24.

Vierheilig, H., Coughlan, A. P., Wyss, U., and Piché, Y. (1998). Ink and vinegar, a simple staining technique for arbuscular-mycorrhizal fungi. Appl. Environ. Microbiol. 64, 5004-5007.

Xia, Y.-S., Chen, B.-D., Christie, P., Smith, F. A., Wang, Y.-S., and Li, X.-L. (2007). Arsenic uptake by arbuscular mycorrhizal maize (Zea mays L.) grown in an arseniccontaminated soil with added phosphorus. J. Environ. Sci. (China) 19, 1245-1251.

Zhao, F.-J., Ma, J.-F., Meharg, A. A., and McGrath, S. P. (2009). Arsenic uptake and metabolism in plants. New Phytol. 181, 777-794.

Zhao, F.-J., McGrath, S. P., and Meharg, A. A. (2010). Arsenic as a food chain contaminant: mechanisms of plant uptake and metabolism and mitigation strategies. Annu. Rev. Plant Biol. 61, 535-559.

Zhu, I., and Altmann, S. (2005). mRNA and 10S-RNA coapplication-reverse transcription for quantitative gene expression analysis. Anal. Biochem. 345, 102-109.

Zhu, Y.-G., Smith, F. A., and Smith, S. E. (2003). Phosphorus efficiencies and responses of barley (Hordeum vulgare L.) to arbuscular mycorrhizal fungi grown in highly calcareous soil. Mycorrhiza 13, 93-100.

Conflict of Interest Statement: The authors declare that the research was conducted in the absence of any commercial or financial relationships that could be construed as a potential conflict of interest.

Received: 10 January 2012; paper pending published: 31 January 2012; accepted:
25 March 2012; published online: 13 April 2012.

Citation: Christophersen HM, Smith FA and Smith SE (2012) Unraveling the influence of arbuscular mycorrhizal colonization on arsenic tolerance in Medicago: Glomus mosseae is more effective than $G$. intraradices, associated with lower expression of root epidermal $P i$ transporter genes. Front. Physio. 3:91. doi: 10.3389/fphys.2012.00091

This article was submitted to Frontiers in Plant Physiology, a specialty of Frontiers in Physiology.

Copyright $\odot 2012$ Christophersen, Smith and Smith. This is an open-access article distributed under the terms of the Creative Commons Attribution Non Commercial License, which permits non-commercial use, distribution, and reproduction in other forums, provided the original authors and source are credited. 